\title{
Experiences of Delivering a Public Health Data Service
}

\author{
Emma Simpson, Rob Comber, Andrew Garbett, Ed Ian Jenkins, Madeline Balaam \\ Open Lab, Newcastle University, \\ Newcastle upon Tyne, UK \\ \{emma.simpson, robert.comber, a.garbett, edward.jenkins, madeline.balaam\}@ncl.ac.uk
}

\begin{abstract}
The turn to in-the-wild within HCI has given rise to an increasing concern around designing technologies which are available at large scale. Uniquely, at the intersection of public health and HCI, our work has supported the deployment of a mobile application, FeedFinder, over the last three years. We delineate the ground-work that was required to sustain this mobile application over the longterm. Focussing in particular on efforts made to engage institutions in taking ownership over FeedFinder and the data it provides, we reflect on the tensions that arose between users and civic institutions, particularly around "what matters'. We provide a reflection on key requirements when designing a health data service and provide three lessons learnt which can guide researchers toward their own successful and productive long-term research deployments.
\end{abstract}

\section{Author Keywords}

User-centred design; public health; breastfeeding; citizen-led data;

\section{ACM Classification Keywords}

H.5.m. Information interfaces and presentation (e.g., HCI): Miscellaneous;

\section{INTRODUCTION}

The turn to-the-wild in HCI focusses on how communities engage with and make sense of technology for their everyday use [19,26,27,51]. More recently, research on in-the-wild deployments has seen a shift in discourse around understanding technologies in situ - not only for the short trajectory of a research project but for the extended engagement over the long term. This shift in discourse has presented new ways of thinking and reporting on designing for prolonged use and larger scale deployments [39,50-52], where typically, this information would be absent from publications [51]. The notion of prolonged use, and large (even global deployments) is increasingly important within HCI, particular when prototypes or tools have been developed to support political activism, community

\section{(c) (7)}

This work is licensed under a Creative Commons Attribution International 4.0 License.

Copyright is held by the owner/author(s).

CHI 2017, May 06-11, 2017, Denver, CO, USA

ACM 978-1-4503-4655-9/17/05.

http://dx.doi.org/10.1145/3025453.3025881 engagement, or health-related behaviours. We provide a substantive contribution to this field and particularly draw attention to the neglected human and social work needed in place to promote the success of these technologies. In particular, we attend to the work undertaken to engage public service providers in the long-term sustainable use of a digital civic service, in this case a public health data service. We focus our attention on 'what matters' to both users and civic institutions. In doing so, we highlight the tensions that arose and provide some key reflections to help guide the design and development of other health data services; designing for action, designing for negotiation and designing for monetization. In contrast, our lessons learnt delineate what support is needed from a research perspective for a successful and longer term deployment.

Our work is situated at the intersection of Public Health and $\mathrm{HCI}$, and based upon a mobile application that has been used in-the-wild for over three years. FeedFinder [1] is a free mobile application, available on $\mathrm{iOS}$ and Android. It was developed with the intention of creating a supportive health technology around which women could make the decision to breastfeed in public. It allows users to find and review venues for their breastfeeding friendliness on a map. Launching in July 2013, FeedFinder has been running at time of writing for over 36 months and has seen an uptake of almost 10,000 users worldwide. The data within the application has been contributed by the breastfeeding community, leaving around 3000 reviews across 3200 different venues. FeedFinder is thus situated alongside a range of crowdsourcing tools, enabling collective civic intelligence that empower citizens to take an active role in decision making and influence services they receive [2,26]. FeedFinder has continued to sustain user registrations and contributions over the last three years, and as it has continued to grow we routinely hear positive stories about its impact from women, businesses and the institutions that support it. But, clearly this has not just 'happened', and one of the goals of this paper is to illustrate and discuss the work involved in maintaining a successful research prototype and growing it into a digital civic service. To do this we reflect on the last 13 months of research and engagement activity around FeedFinder, predominantly focusing on engagement with public service providers and support staff, discussing the research and the 'other' work we have done to sustain FeedFinder and its community. We contribute a qualitative understanding of how a breastfeeding 
public health service used FeedFinder data to inform their services and a set of principles for supporting a 'public health data service'. We finish by describing a set of lessons we have learnt through the successful and long-term deployment of our research product, FeedFinder.

\section{RELATED WORK}

Recently there has been a surge in research aimed at exploring the role of such technologies in influencing city infrastructures and services $[7,27,34,45,50]$. Collaboration between citizens and civic workers through the medium of technology is on the rise. The ubiquity of mobile technology has enabled citizens to actively take part in new forms of civic engagement - involving city planning [7], providing opinion [50] influencing city maintenance [16,30], commissioning of their own location-based review apps [18], and becoming involved in political decisions [57]. Yet, despite this growing interest, there are still limitations with this work. In particular, a review of protocols around datause suggests that often the data are used in relatively controlled research environments with little reflection on the prolonged engagement beyond a research project $[7,27,34,50]$. Traditionally, the use of apps and sensing technologies is at the heart of this research but app-oriented projects often suffer from longevity and sustainability issues [34]. A lack of funding and resource constraints, including technical support can often lead to an application becoming unsupported once a project comes to an end. At other times, without sufficient researcher engagement an application just ceases to be used. As [26] notes, any concept of prolonged engagement and visions of civic authorities and citizens acting as partners is far from yet achieved.

\section{Data and Public Health}

Advances in social computing and social media technologies have significantly changed the landscape of public health $[5,25,49]$. Communities are now able to create and share credible knowledge-based experiences of dealing with or responding to public health issues while increasing community wellbeing $[1,5,17,21,22,25,28,41,42,49]$. Coined 'Public Health 2.0' - this movement could enable open and collaborative efforts between health experts and specific communities to tailor public health services and interventions to the specific local needs of a community. Central to the success of the Public Health 2.0 endeavor is the vested interest from community members to act responsibly, participating and creating good quality content based on the common values and needs they share. There has been a growth in recent research aimed at understanding how communities in online forums such as PatientsLikeMe [44] are taking charge of their own health through sharing their lived experiences of living and dealing with their health conditions with one another. The premise of online health communities has confirmed that users often feel empowered, more confident, better informed and more likely to 'feel a sense of control over their future' while increasing confidence of interacting with healthcare providers $[35,41,55]$. Similarly, other online platforms are enabling citizens to advocate for better services based on reviewing their experiences with a particular practitioner, practice or hospital service [43]. This approach has been used predominantly in the US where healthcare is provided at a cost, and therefore patients want to ensure they are receiving the best possible care and treatment for their money. More recently in the UK, this approach has been harnessed by 'Patient Opinion' [43]. Ran as a social enterprise, the website boasts over 600 registered health services that are automatically sent feedback from the website when citizens leave a review. The review process is tracked and change documented, with a reported $10 \%$ of the reviews resulting in a positive change [43]. These new forms of engagement are shifting the move from what would traditionally be transactional to a more relational service model, reconfiguring power relations between communities and their service providers [58]. Despite this, little focus has been given to the impact of these new forms of communication and interaction on local public health service provision.

Although there is little academic research in this area, we also look to commercial reviewing services such as TripAdvisor [54] and Yelp [59] as inspiration for how something similar might operate within a public health context. There are however, clear contrasts between what would be a public health data service and that of comparison in the commercial sector. With the latter providing a platform for dialogue between businesses and the public, whereas a public health data service we would consider to be much more complex. In a public health context, multiple stakeholders would have an ability to act on potentially damaging reviews (e.g. affecting well-being of mothers/infant), but are also bound by certain factors such as local authority service level agreements [38], legislation or policy [15]. In a commercial review site, a business is likely to engage with a negative review to maintain footfall and reputation, but with breastfeeding for example, businesses seemlingly have less motivation to be engaged.

In the wider context of Public Health and HCI, conversations around the benefit of 'Big Data' are often shrouded in doubt [29,32,37]. 'Big Data' and citizen-led data collected through social computing channels has been discussed as a proxy for disease outbreak surveillance [32] but research in this area is very much in its infancy. On a smaller scale (i.e. at a local level) there is scope for citizen-led data to be used in practice to influence the type and quality of public health services that are received, perhaps in the guise of 'little data'.

\section{Data in Collective Action}

Social media technologies have been considered an instrumental and significant resource for collective action and social change [14]. In the wake of the crisis mapping phenomenon, scholars have reported how these applications have provided a vehicle for empowerment and better still'saved lives' [2]. The appropriation of CrowdMap [6] to Ushahidi [40,60] and HarrassMap [23,24] has enabled citizens to become active agents in collective action and 
change the response to reporting disasters and crime. Scholars have recently turned to understand how these technologies can be re-appropriated for community development [2]. The difference being that the crises mapping tends to be of a short temporal nature, whereas in community development (e.g. crises such as housing, poverty) the applications require more persistent use and over a long period of time. Researchers have described how those working in community development can leverage the crisis mapping platforms and tap into tacit community knowledge while creating greater ownership over the process and data collected to influence organised interventions within the community [2]. Similar to other projects [7] these studies often recruit contributors to input data, incentivising the contribution of data by informing study participants that the data will be used to influence decision-making.

Other work in HCI has expressed the importance of translating data and designing to express matters of concern within a community [11,21,31]. DiSalvo et al [11] describe the notion of designing for 'publics' around environmental matters of concern. In recent years, Dewey's notion of 'publics' has been restored and renewed through shared interests across disciplines (namely social science and $\mathrm{HCI}$ ) $[7,8,11]$ and we consider these theoretical underpinnings are transferrable to the context of public health and HCI. Where constructed 'publics' is described as groups of diverse stakeholders brought together by identifying and expressing a social condition $[7,9,10,12]$ - we can apply this to the context of breastfeeding. Where technology supports the formation of publics and occurs at the intersection of the socio-technical interactions between negotiating expression of issues and supporting the action taken in response [8,9]. A challenge for us then, is designing for 'communities-inpractice' where common social objectives already exist and are supported by 'relatively stable infrastructures' [13,31] The question is, how do we get them to adopt a change in their practice in this digital era?

\section{FEEDFINDER: WHERE ARE WE NOW?}

FeedFinder was launched in July 2013, and since this time, has received over 12,500 downloads of the app $(67 \%$ on iOS), of which almost 10,000 have led to registered users adding near to 3,200 individual places, and over 3,000 reviews (see Figure 1). The service has been primarily used in the UK, however a growing number of venues and reviews have been added in the USA, Western Europe, Australia and Asia. The breastfeeding community are able to find, rate and review places in their locale based on their breastfeeding friendliness. Co-designed with breastfeeding mothers [1], the app contains criteria which are considered important for meeting their breastfeeding needs. Since the launch there have been a number of updates to the application, with new features added. This includes a better search functionality, users being able to upload image of a venue, 'like' other reviewers' and comments as well as share their review or other reviews onto different social media platforms, i.e. Facebook and Twitter. During this time, we have made some efforts to attract users and sustain our community, including the use of print materials, attendance at 'breastfeeding picnics', and facebook advertisements. Nevertheless, the majority of our users hear about FeedFinder through wordof-mouth.

Given its reported role in supporting women in some communities breastfeeding outside the home, we have made substantial efforts to sustain FeedFinder and work with local civic institutions who are at the forefront of breastfeeding support services. Quantitative analysis of user interactions with FeedFinder [1] highlight that users will typically engage with FeedFinder over a three-month period. As such, there is a need to continuously raise awareness of the application among new and expectant mothers to ensure the FeedFinder map is kept up-to-date and relevant. We understood that breastfeeding support services, based on their outreach, networks and activism would be well placed to support the promotion of FeedFinder over the long-term. We also believed that a number of organisations might have a vested interest in the data FeedFinder collects. We hoped in particular that the organisations would be motivated to act on reviews on the FeedFinder map, i.e. contacting businesses who had received negative comments, or low star-rating and commending businesses who were receiving consistently good ratings. This, we imagined would enable women to graduate from simply having a voice about breastfeeding services within the community, to having a say [47], through impacting on the delivery of services.

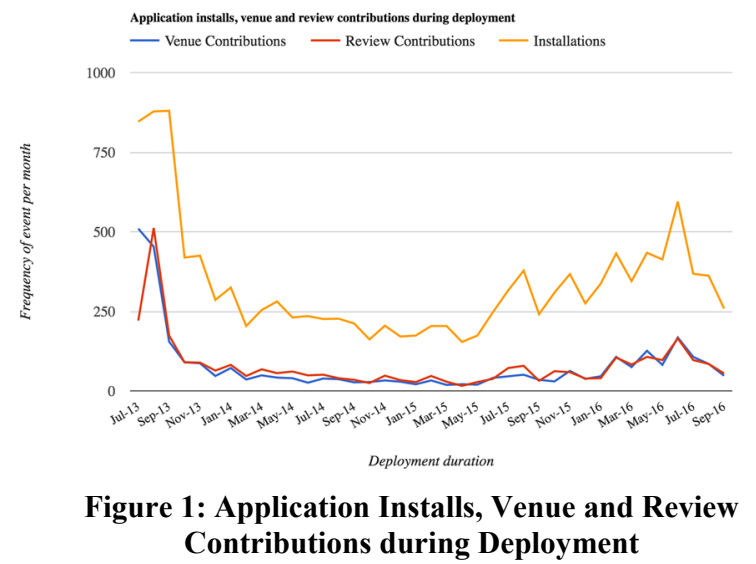

The commissioning of local breastfeeding support services is part of a wider agenda by Local Authorities to improve public health. A contract (Service Level Agreement - SLA) between the Local Authority Public Health department and community breastfeeding peer support services determines their responsibilities Currently, within the UK many breastfeeding peer support services are responsible for working toward gaining accreditation from the UNICEF Baby Friendly Initiative [56]. In short, meeting specific criteria set out by UNICEF will provide an award in receipt of recognition. Part of this criteria includes a 7-point plan aimed at sustaining breastfeeding in the community. 
Particularly relevant to FeedFinder is point 7, co-operation with the local community. We considered that FeedFinder provided a tool through which breastfeeding services could co-operate with the local community to understand a wide range of local women's experiences of breastfeeding, as well as act on the reviews (where necessary).

\section{CONTEXT, METHOD AND ANALYSIS}

This paper reflects on 13 months of work supporting FeedFinder, from April 2015 to May 2016. When data collection began for this study, FeedFinder had been in continuous deployment for 2 years. Much of this work is situated in Newcastle upon Tyne within the North East UK, a city chosen specifically because of FeedFinder's dense use, and the local government's prolonged support of the project. UK-wide breastfeeding rates vary significantly between regions $[4,33]$. On average, $46 \%$ of all babies are exclusively breastfed at 1 week and $1 \%$ by 6 months [33]. Differences are seen across the UK but the North East of England has the lowest rates of exclusive breastfeeding compared to other regions at one week and 6 months, 36\% and less than $1 \%$, respectively. Society has a collective responsibility to provide a supportive and enabling environment for women who want to breastfeed [46]. The recent transition of public health services from the primary care sector to Local Authority has already exerted considerable financial and resourceful strain on services, with an additional call to cut $£ 32$ million to Newcastle City Council services in the coming year [38].

As motivated in the previous section, a great deal of our focus has been on establishing relationships with breastfeeding support services and developing a service design which would enable them to incorporate FeedFinder into their service provision. Over the last 13 months we had conversations with multiple stakeholders working in breastfeeding support - some of which proved successful, leading to further collaborative work and promotion of FeedFinder, while others were without fruition. In addition, the authors interviewed FeedFinder users (12) to understand how they use the application, as well as their experiences of use. We have held meetings with two managers of a breastfeeding support team, a midwife, an infant feeding coordinator and midwifery research nurse and attended a number breastfeeding support working group meetings (including children's centre staff, health visitors, physical activity coordinators, midwives, breastfeeding peer support workers and volunteers). The first and last author have given talks at a range of regional and national events about FeedFinder, and its impact on breastfeeding support. The first author set-up a Twitter account in an attempt to raise the profile of FeedFinder more generally. We established a longer-term working relationship with a breastfeeding support service in the city who are commissioned by the Local Authority to provide city wide breastfeeding support. The first author attended local breastfeeding support groups meeting peer supporters and breastfeeding women. Over the course of a year we attended the monthly meetings of the breastfeeding support services and kept in touch via email during the periods in between.

Through these conversations (interview, focus group and email) we identified a myriad of issues and strain on the breastfeeding support services. Firstly, most of the service providers we have spoken to haven't been able to monitor breastfeeding support in the community, and as such are not fulfilling a key part of the UNICEF baby friendly initiative described earlier. In addition, while service providers have attempted to provide print materials and resources for breastfeeding women, particularly on 'breastfeeding friendly venues', these have quickly become outdated and redundant without scope for any replacements. In addition, we have discovered that there is no universal breastfeeding policy that they can provide for businesses to ensure consistency in the community. Finally, although many of the support workers had heard about FeedFinder, they hadn't used it themselves, or seen it used in practice. Promoting the application was part of their service delivery plan, but none of the team had the app installed on their own mobile phones or were aware of how the app worked.

We report data from interviews, working group meetings, focus groups, field notes and observations. All instances of recorded data were transcribed verbatim and we adopted an inductive thematic analysis approach [3]. Each transcript was manually coded and NVivo 10 used to group codes into hierarchical themes which we present in this paper.

\section{FINDINGS}

Our goal was to understand the ways in which FeedFinder could become part of a public health data service for breastfeeding support services. We wanted to explore the potential uses of the data in practice, how this data should be made available as part of a service, as well as the ways in which the support service could work with us to help sustain the FeedFinder community. Throughout each monthly meeting the first author discussed the group's use of FeedFinder, their efforts at promoting it, and in addition an exploration of the 'live data'. The live data included free-text reviews on venues within their locale, star ratings for the venues (based on the criteria within the app, namely hygiene, privacy, comfort and baby facilities) and looking together at the FeedFinder map. We were particularly interested in whether and how the service thought they could use the data. We present the findings here under the following themes: accessing and unravelling the data, institutional and professional support, adding to the map and encouraging use, and finally, 'Whose job is it anyway?'

\section{Accessing and Unravelling the Data}

We set out to explore what it would mean for breastfeeding support services to have better access to data that could potentially impact on their service provision. It was immediately clear that access to the data was troublesome for the support service. Few had FeedFinder on their phone, but even when they did it was evident that the mobile application itself did not provide the required regional overview, or 
necessary filtering options. As currently designed, support workers would have to investigate all individual places and reviews to find opportunities for action. In addition, it was virtually impossible for the support service to identify recently added places or reviews. This gave rise to the necessity to develop a web-based interface for the data which would give a higher level view of the data collected by FeedFinder.

As we discussed further the needs of the breastfeeding support teams in accessing and acting upon FeedFinder data, the ability to compare data across administrative areas of the city (known as 'Super Output Areas') became a significant requirement. This enabled them to monitor areas of lower socio-economic status where it was expected by the support teams to be less common to see a breastfeeding woman in public. As Marie details: "I think if you're looking at super output areas...like at the moment we're focusing on the west...obviously we're working there so we can look and if one of our areas is a two [breastfeeding friendliness rating] then we can look at it and one of our goals could be can we get it up [breastfeeding friendliness rating]?"

While we began the design and development of this interface, the first author became responsible for trawling the application on a monthly basis to identify and gather reviews, using her discretion, that were in need of discussion, and presenting these to the support service. However, on presenting reviews - aimed at provoking a detailed response to how they would act quickly - the group became entangled in much more nuanced debates about the contextual factors. Using their own experiences to compare, they debated at length whether the data would actually warrant any action in response. At times, they described the evidence as 'weak' and called for a process where they could retrieve further information from both the women and or the business owner for confirmation and to look at it from a 'factual point of view'.

Kate: but that's the thing isn't it, I mean it says 'not a great place to feed not enough room' but again they might have twins or they might have a child and then two other toddlers.

Marie: I think whatever they write you...

Kate: have to read between the lines a bit...

When discussing the data, they described how it became a matter of subjectivity and proposed numerous questions they would ask the woman who left the review. In response to this, they proposed ways we might further improve FeedFinder to be a useful resource for them. They suggested a social element, where they are able to respond to the women and ask for further information.

Marie: so that one there I would say, ok, not a nice place to feed, not enough room, I would pick out the bunch of all of these [reviews] and if the lady has left the name and contact number [imaginary scenario] and then you can get a bit more detail, what do you mean by not enough room, ... because it could be arms on the chair, it could be the door opens inwards so you can't get your buggy in and shut the door, or it could be I've got twins, you know, so it is reading between the lines, but that is a potential option for a person to leave their [contact details]

It is notable that most of the dialogue around the data was framed in this way - seeking out the social and contextual factors which could have contributed to a woman's experience, and the possibility that a woman may have made a misjudgement which could be further clarified by speaking with them or with the business.

Marie: "staff skirted around the subject of breastfeeding so we didn't receive a clear answer", so she obviously asked, but what was the questions...

Jodie: "maybes a telephone call to the Centre X or you know, its whether actually she asked...they might have actually given her somewhere else, she might have assumed that this is where I need to sit when actually that chair might have been for a toddler..."

As they suggested ways in which the app could be further developed to allow for contacting the women to clarify their experience, they also desired to let women know their review was valid and had been taken care of "would you then, say if you sent that email to say Store $X$ or whatever would you then comment underneath about what you had done" and further "I think to reply to a comment to say 'hello we will look into this' or something is great, you know, to show that something is happening".

However, we observed differences between the idea of what's important and 'valid' when breastfeeding in public, with contrasting views from the breastfeeding women and those who provide support. In the context of breastfeeding and changing facilities, Fiona, a FeedFinder user and breastfeeding mother described "I do tend to share, kind of, baby changing and feeding facilities because they often go hand-in-hand". While in contrast, the breastfeeding support team overlooked much of the data that made reference to changing facilities and were more interested in whether a venue was welcoming of breastfeeding, regardless of the changing facilities. Talking about amendments to the FeedFinder app to help guide women to talk less about facilities was mentioned by Jodie... "that's what you want to know, whether they are breastfeeding welcome but if we're going right oh well that says about the baby facilities but we don't want to know about that but we're asking them to star it, so I would scrap that and have is it breastfeeding welcome' [instead of baby facilities]." At times, they explicitly described how they were "not interested in a place being child friendly' but rather 'are they able to breastfeed'. This was also reinforced when they questioned a woman's choice of venue after she reported that the place wasn't child friendly, however they also suggest a business has a right to respond. 
Jodie: "the thing is with this, because whether or not you, because it is Franco Bollo, whether or not there is some sort of email that goes to them or another establishment that says 'just to let you know we have received a review, blah blah blah'. and I do feel quite strongly you have got to give them the right to reply [the business], so they have to know, well they might say our staff, well I don't know..."

Marie: "but then Franco Bollo there's a flight of stairs but there's seats downstairs"

Jodie: there is but that's not our issue, our issue is not about being child friendly, it's about breastfeeding

Marie: "I think the issue here is she is saying it was happy for breastfeeding, the other issues are about the stairs and position next to a large group sometimes that is way out of our hands, we can't, that is their choice of venue, they have chosen a venue that has got a flight of stairs and no lift so it's not baby friendly but they are not saying it's not breastfeeding friendly"

However, there were times when the breastfeeding support staff looked beyond their service level agreements and unpicked the data from the perspective of having been a breastfeeding mother. Drawing on their own experiences to sympathise when places don't provide the space to change and feed separately, Jodie recalls "the baby changing is the toilet for babies so why would you make that the feeding room? it causes bad feelings for people waiting to change their babies because if you're feeding in there and there's a queue of people waiting to change then you come out, because I've experienced it, people will be glaring at you.",

Interestingly, some of the conversations around the data were contradictory. We discussed the implications of a wellknown health department store having directed a woman to an outside disabled toilet in order to feed, with Jodie (breastfeeding support) questioning whether the review was correct: "there is, they have got, ah I might not have been in that one, but most [of the stores] have got a feeding room". A similar response from a DIY store where a woman was shown to a ladies' toilet and given a stool to sit on was applauded, rather than chastised for encouraging a child to be fed in a place where previously they questioned: "when somebody says oh you can go to the toilet and breastfeed would you go and eat your dinner there?" rather than "well done not just you know, what's that like a s**t sandwich, well done for doing this, the place was awful but??" This rhetoric around breastfeeding reflects other research within the field of breastfeeding qualitative work [53].

\section{Institutional and Professional Support}

We take the position that an institutional seal of approval will likely help in promoting FeedFinder, and have discussed FeedFinder at a range of National Health Service events, raising its profile among breastfeeding activism groups (such as the National Childbirth Trust and La Leche) with varying levels of success. These concerns around what it means to provide support for such an application are well illustrated by our conversations with the breastfeeding support service and other FeedFinder users over the last 13 months. In some cases, support workers disagreed with the premise of the application, and suggested they could not endorse it. They suggested, for instance, that a 1 star review in the application would suggest that somewhere was not breastfeeding friendly - in direct contradiction to UK policy on breastfeeding. Concerns were also aired when the support services realized that their right to anonymity was waivered depending on their chosen user name when registering in the account on the FeedFinder app. This prompted dialogue around whether or not they would want to be identified by their own name when acting as a professional.

Jen: "nobody would know like my name for example, you don't have to put your full name, do you, like JC or jenc, but no one would really know that is me as a person, especially if you don't put a picture, if you don't make a full profile, if $I$ made a profile to say I'm from City X breastfeeding support, blah blah, then you know... I don't think I would put a picture on, and I've left a few reviews at different places that I have been which aren't related to work but I've thought it would be nice here [to breastfeed]"

Here, Jen is concerned that 'outing' herself as a breastfeeding support worker might have implications for how her reviews are received and understood by the community, and potentially also businesses. She both doesn't want to be a target, or be concerned that everything she adds to the FeedFinder map is viewed in this 'official' capacity. This was also the case for some of the breastfeeding mothers we interviewed. In particular, one of our breastfeeding women was a General Practitioner (family doctor) and because her username on FeedFinder was her full name, this meant she would be identifiable - preventing her from leaving reviews around the place where she practiced, for fear of people assuming it was her professional view. As she describes, "There was just one thing I did. When I logged on it says, "Have a username," and I'd actually just used my name. Then I can't change it. So I thought people would know who I am. Not that it's a huge problem for up here, but I'm a GP down in City A and so I wouldn't want people in City A knowing I'd left the review...so it's trying to keep that anonymity. Especially with maybe some of the smaller places you might leave a review for, they might know who you are. I can't change it now so I have to keep that. So that might stop people putting reviews down for, like, little local cafes if they've actually put their name down as their...

We also explored the potential of sharing reviews on social media. As a new feature, we see this as an opportunity to open up the data for discussion online, but again, anonymity was a contributing factor which would inhibit a woman's decision to share reviews. As Katrina (breastfeeding mother) describes: 'I think again, it's a professional thing that you're told, you know, as teachers or doctors to be very careful about what you put on. If I shared something, but somebody had put on a really out-there review then I might be seen to 
be promoting that. So I'd be very careful about that.... I probably wouldn't share it on social media, because then I'd be seen to be promoting it. I mean, promoting breastfeeding is a great thing but if somebody's written a dodgy review and I hadn't read it, you know, just for those kinds of reasons. Such views are not unique to Katrina. There is much concern across many of the institutions we have spoken to about FeedFinder which have focussed on the uncontrollable nature of social media, and user-generated content. As such, many of the conversations we have had with institutions have concluded that it would be necessary to view and agree with every review added to the map before institutional support for FeedFinder could be provided.

Additionally, the idea of a mobile application which supports breastfeeding is problematic for some members of the public health community. There were clear contrasts in the views posed by both the breastfeeding women and the breastfeeding support services. As Marie (breastfeeding support) noted, "we discourage women from using their phones when nursing as it is a distraction and they should be bonding with the baby". This conflicts sharply with modern parenting practice [20], as described by one of our FeedFinder users: "Yes, it's usually if I'm feeding him or something...like lots of people I'm glued to my iPhone...I think where I've been, yes, I do it in blocks [add reviews]".

\section{Adding to the Map and Encouraging Use}

As we have mentioned, the support team often questioned the data from the women in FeedFinder. In doing so, they raised doubts on the legitimacy of some of the data which resulted in them seeking to find out further information before considering a response. One way in which they did act however, was to populate the FeedFinder map with the women at weekly breastfeeding peer support groups. They also discussed the idea of incentivizing the volunteers to take on the role of reviewing places and inputting into the FeedFinder app. To encourage them to carry this out the staff discussed the idea of providing a 'prize' for the most reviews left or the best review.

Marie: "something that we could do is get the volunteers to go out there and try different parks and then say to them on top of that go and put your review on FeedFinder"

Jen: is it worth me emailing all of our volunteers that we know have got a baby, sorry or breastfeeding or pregnant and saying it's like a little project for them?"

Marie: "we could send an email out to volunteers to generate interest again about [FeedFinder] or if they are finding it difficult or if they haven't, or they don't do apps and things if they forward the information we can put it on for them"

Jodie: "We could even put on a little prize for who gets the most increase of reviews or best..."

Jen: "I definitely see where volunteers fit into this, I mean because asking them to go out and about in their particular area to review establishments and or spread the word, obviously some of them are still breastfeeding, I just think it would be a nice volunteering opportunity for them without...it feeling like they have to do it... apart from that it's good from this point of view on this side too of trying to raise standards and raise numbers, so..."

In addition, the breastfeeding support team, alongside multiple other organisations, requested paper-based promotional materials to help the breastfeeding support teams to promote FeedFinder. In response, we have designed and printed a range of different 'marketing' material to help partners and organisations promote FeedFinder on our behalf. We have been told that stickers are useful for putting on 'baby books' (an NHS record resource for a child given to mothers after they give birth) when health visitors or breastfeeding peer workers first met with a woman after giving birth. Leaflets and cards have also been requested by other service providers over the last 13 months to be used alongside conferences, meetings and breastfeeding picnics to help raise awareness of FeedFinder among healthcare workers, volunteers, and new and expectant mothers.

As we talked about promoting FeedFinder within the local community it became clear that regional competition could also function as a very poignant motivation for local service providers. Breastfeeding support workers often talked about 'doing better' than the adjacent cities in terms of breastfeeding rates and breastfeeding community support was an important sense of achievement "oh we have got to beat City Y and City Z". This became of such importance to the breastfeeding service that we worked with that we agreed to incorporate a unique tracking link (for the service provider) on the leaflets and stickers we produced for them so that they would be able to track their 'download' rate in comparison to other services.

\section{Whose Job is it Anyway?}

In many cases, although the support workers had good intentions, any actions they would consider were either delegated to the role of a volunteer or directed toward the first author 'you could just draft two standard emails', 'you could contact businesses', 'you could ask the women for further information'. There was a particular onus on us to take responsibility for the actions around the data. We had envisaged this to be a useful resource which would enable the service provider to monitor community support, opening up access to information which they were lacking previously. Instead, we were reminded frequently with reference to their contract (Service Level Agreement), any actions would be beyond their scope of work. Through working together the responsibility for action was pushed back to the researchers or when money came into the equation - on the business to pay to receive their services.

Jodie: "So could we not just like, draft a letter?"

Marie: "No, its capacity for our team when it's not in our SLA."

Kate: "Unless someone is going to give us some money?" 
Jen: "Do the businesses know this exists [FeedFinder], they should do."

Jodie: "I mean just a letter, not send it out but give it for \{researcher\} to send out."

Jen: "But what you going to put in that letter to improve on their services?"

Marie: "You can't just say - "I don't know if you would like to discuss it more and like a bit more understanding" I'm happy to use the central line for them to ring us but we can't offer them any training we haven't got the capacity and we don't get paid for it."

Kate: "But it's you [the researcher] that would do that?"

Jodie: “...we could get them to pay us for it, get the business to pay for it...come in and we deliver a session for $\$ 10$ all your staff. You know, you would get a certificate at the end of it to put in the window to say we have all been trained."

Despite considering that FeedFinder could provide the support service with easy access to data which they would need to fulfil elements of their service level agreements, how the organisation would use it in practice opened up a range of issues which were considered to increase the workload of the service. The disjoint between how the breastfeeding community wanted to rate, describe and share their experiences, versus the means by which the support service construed a positive breastfeeding experience, meant the service felt they would need to further clarify women's comments before action could be taken, further increasing demand on their time.

\section{DISCUSSION}

We have presented in this paper experiences of running a longer-term research project involving a sustained, three year long, in-the-wild deployment. Our documented experiences over the last 13 months of supporting FeedFinder, and in particular a year-long engagement with one breastfeeding service provider in the city, has identified the necessity for a web-based interface to allow better access to the FeedFinder data. We have identified key service design requirements that would enable this data to lead to real-world impact, and ultimately an improvement in services by multiple stakeholders (i.e. not just breastfeeding women). We are also concerned with making FeedFinder sustainable and passing ownership from us the 'researchers' to the communities and institutions that FeedFinder serves. Women see the benefit of FeedFinder in describing the public breastfeeding context but there's not enough resource to affect change [1]. We need the engagement of other key stakeholders and to influence policies to make that happen. We are currently in the process of designing and developing the web-based tool with a number of local service providers. Here we reflect on the requirements for a 'public health data service', finishing by presenting three lessons learnt which can be used by researchers working in the field to guide future long-term deployments.

\section{A Public Health Data Service}

Public health service providers have the option to engage with citizen-led data or not. Technology acts as an enabler for the collection of large datasets which would typically be difficult to collect and manage in a public health setting. A salient and often unanswered question when working with citizen-led data is 'how do we design to transform data for use in practice?' Citizen-led data can be messy, unpredictable and the challenge we are faced with is how to design interfaces that increases access to the data while visualizing it in a way that is beneficial, reduces labour and is a useful resource [2]. In addition, we have to consider the possibilities of designing for those with limited technical expertise, making it simple, engaging and intuitive as well as practical for those working in the field.

\section{Designing for Action}

In positioning FeedFinder as a 'DingPolitik' [1] we frame FeedFinder as a technology through which lived experiences of political conditions can be better known, and acted upon. While we recognise FeedFinder as an application which offers women a voice in sharing their experiences, it doesn't necessarily offer a 'say' [47]. Over the last three years we have witnessed some users utilising our dataset to create change in their community, but these have been in a minority [1]. As a result, we have created a condition, where women can voice concerns and experiences, but few institutions or organisations appear to be listening or acting. As found elsewhere there are challenges to working with communities bound by contracts and infrastructures [13,31]. In our case, working with a breastfeeding support service over the last year has emphasised the lack of time and resource these services have, particularly when delivering on anything but non-essential frontline services. In many ways, this is unlikely too different to the situation and experiences of a new mother, who similarly will struggle to find time for anything but the essentials.

A 'public health data service' should enable action. Taking inspiration from social platforms for change, such as Change.org, we have learnt that time for action is limited, and that taking action should be as simple as clicking a button. We consider, that alongside providing relatively standard review, search and filtering features, a data interface should automatically highlight places where action may be required. Similarly, other health data services such as [7] could also enable action - it could allow health professionals to identify areas where more support for physical activity is required. Other review based health data services like [43] provoke action among service providers where the quality of care is lacking. In our case, for example, we can identify places where venues are on a downward or upward trend (in terms of breastfeeding friendliness), areas within a locality where number of users is waning, or gaining momentum. Much like the support service whom we engaged with suggests, the data service should provide templates of emails, leaflets and posters which users (whether they be 
breastfeeding activists, breastfeeding support workers, or otherwise) can quickly download, adapt, print and circulate.

\section{Designing for Negotiation}

In discussing reviews with support services we were intrigued by the level of meaning making undertaken by the group. An experience shared by an individual was rarely taken at face-value, but instead dissected to identify whether action was necessary, or whether the women's experience was as should be expected. We found the support service providers regularly drew on their own experiences, as well as an institutional perspective on breastfeeding friendliness, to assess the legitimacy of a review. Similarly, to $[2,7]$ we have found that the service providers own values and experience shape how the data is interpreted and ultimately how it is acted upon. Complex disputes and issues around data interpretation and analysis have been reported elsewhere [34]. A resolution suggested by the authors and what we agree with, is that specific criteria must guide the collection of data if it is to prove to be sufficiently useful to an outsider (i.e. those who didn't devise the data collection initially). Moreover, [50] highlights the issues that may arise by looking at data through an 'anti-perspectivist lens', explaining that such a data-as-truth view could cause damage or lead to a troublesome outcome if data is acted upon without considering the ethical implications.

A 'public health data service' must thus enable negotiation of data collected, as well as negotiation of the criteria around which experiences are reported. In our case, the rating criteria for FeedFinder were established through a series of user-centred design workshops with breastfeeding women, where we privileged a woman's breastfeeding experience, over outcomes, practices or policy understood from an institutional perspective. Consequently, factors such as baby change facilities (which are part and parcel of intimate care of a young baby, alongside feeding), were selected as a crucial criterion for rating venues. But, such a criterion, according to the support services we have worked with, has nothing to do with breastfeeding friendliness. By designing to enable negotiation we envisage a scenario where breastfeeding support workers could propose alternative criteria to the community, based on their needs for the data. These new criteria could be voted on, and where appropriate incorporated into the application for women to use goingforward. Platforms such as App-Movement [18] could incorporate such phases of re-design into applications, when for example operating systems require updates to existing applications. Ongoing dialogue around what constitutes useful data could enable the end-users of the system to understand the value of their voice, leading to further motivation for use.

Trust and moderation of content continue to be an issue for institutions and private end-users, considering reputation to be at stake, if for example FeedFinder was found to contain libellous, or inflammatory reviews. As suggested, an interface which enables support services, businesses and other women to explicitly respond to reviews would provide an opportunity for negotiation of meaning, and appropriate action, akin to review services such as TripAdvisor and Yelp. Commercial services like these provide a platform where diaglogue can occur between the consumer and the business operator, allowing space for negotiation and potential reconcilary action (if need be). Such opportunities to respond may also help to increase confidence in the reliability and trustworthiness of the collected data.

\section{Designing for Monetization}

McMillan [34] highlights that it is often challenging to get service providers to take on additional work such as managing and analysing data without monetary incentives for their team. Neff [37] similarly discusses the implications of data driven work within a healthcare context whereby doctors do not see data as a source of value but rather costly and risky additional work. We experienced the same hesitancy, where the support services were unable to act on the data without extra funding or integration into their working contract by the Local Authority. Working in the context of breastfeeding over the last three years we have become increasingly aware of the lack of policy (national, regional and local) that support businesses, venues and places in being breastfeeding friendly, i.e. clearly specify what this means in terms of facilities available. This hinders service providers' ability to act on businesses which are not supporting breastfeeding (or receive negative reviews), as there are no clear guidelines about what should be in place.

This brings forth an opportunity which the FeedFinder dataset, and the 'public health data service' can provide. FeedFinder is in a unique position to evidence what makes for a good public breastfeeding experience based on a content analysis of women's reviews [48]. Such analysis can be translated into evidence-based policy and services, which in themselves have monetizing potential. For example, services could encourage businesses to sign-up to a 'FeedFinder Breastfeeding Scheme', for which businesses would pay a small fee to receive training based on policy, along with promotional materials and publicity. In tandem, women's use of FeedFinder allows services to keep track of businesses services, without increasing a service's workload extensively. This allows the service to keep-up-to-date with the extent to which businesses are upholding the policy (and potential need for re-training), as well as identify new businesses to include within the scheme.

\section{Lessons Learnt}

Finally, after supporting the deployment of a mobile application for three years (and running), we offer three lessons learnt which we consider to have enabled this unique long-term and engaged deployment within HCI.

\section{Make Yourself Useful}

Over the last three years we have presented FeedFinder at multiple NHS and council run events, discussing in particular the user-centred design process, along with how the application works, and what kind of data we have 
collected. These presentations have led to multiple meetings where stakeholders have wanted to discuss how they might make use of FeedFinder, or indeed persuade us to develop different kinds of location-based rate and review applications for other contexts [see 19]. These meetings do not always lead to concrete collaborations, but they do increase the visibility of the application and the work you are doing.

In FeedFinder, we have created an entirely unique dataset, which offers all kinds of interesting lenses on women's experiences of breastfeeding, geographical differences in these experiences, an evaluative tool for measuring more traditional 'interventions', through to a dataset which describes the structure of uptake and use of grass-root data movements. By finding ways to translate your data into meaningful tools for others (whether this be policy, new methods of evaluation), you can ultimately sustain interest in the application in ways which allow you to continue to support and update it as a product.

\section{Have Assets to Hand}

Throughout the deployment and interactions with external partners, local organisations, and media outlets we find ourselves time and time again communicating the values and affordances of the FeedFinder service. Being contacted by a media outlet, asked to present at an event, or engage with a local organisation has required that, as a team, we develop a common language and branding around the FeedFinder project. This has led to the creation and sharing of key assets, beyond those needed for third-party dissemination, in particular high-quality photographs and logos as well as text based materials (paper-based promotional materials, short overview statements, longer descriptive texts for different academic, healthcare worker, external organization purposes) between team members. These are crucial to delivering a consistent message behind the project but also in responding to opportunities for engaging with potential project partners and organizations to support these forms of services. Perhaps most importantly, What we have come to realise is that these promotional materials are just as much for the service-providers as they are for women themselves. Many of the individuals involved in supporting breastfeeding do not consider themselves to be technical, or interested in technology. In addition, these resources allow us to respond quickly and efficiently to inquiries about FeedFinder. Being rapid in our responses helps to give the impression that FeedFinder is a product, and that the team supporting it are trustworthy and responsive.

We recommend you think early on about a website, a hashtag, a logo and professional photographs related to your product / service. All these assets are key to communicating with your audience.

Think about the Service, Not Just the Application

Much of the time our focus has been on the design, development and re-development of the FeedFinder application. We have focussed on our immediate users, knowing for example, that they value baby-changing facilities as an intrinsic part of breastfeeding in public. This focus has been to the detriment of 'making ourselves useful' to wider services, which may have implications for the longevity of the application. Having now spent considerable time engaging with individuals providing services to communities, we realise that the data FeedFinder collects is not made available to them in ways which are at all feasible given their existing time pressures. We also know that the type of data collected does not always meet their specific needs.

Having only one point of access to data about your application causes bottlenecks. Not enabling every member of the research team to find for themselves how many downloads, how many users, how many reviews, etc, is limiting. We recommend you think early about the wider ecosystem which surrounds your application, identifying opportunities for how the data might be used not only by your research project, but also other key stakeholders. Tools such as Rich Pictures [36] may help here to illustrate all the ways in which different stakeholders might want to engage. Once you know how useful your data is, and the ways in which people will want to use it, implement tools and pipelines that provide access.

\section{CONCLUSION}

This paper has presented a rich description of the work involved in sustaining a successful technology in the wild. We set out to understand how we could encourage local service providers to take greater ownership of the usergenerated data from FeedFinder to potentially impact on their service provision. We found tensions in achieving this, not least in negotiating 'what matters'.

Ultimately, what we want for FeedFinder is for it to translate into a 'public health data service' so that we can ensure this application continues to be made available to women for as long as necessary. We look to develop a service that is not commercially profitable but rather a sustainable service. The principles developed through our engagements with breastfeeding support services over the last 13 months are our intial steps in this process.

\section{ACKNOWLEDGMENTS}

We would like to thank the breastfeeding community for their continued support of FeedFinder. We also owe gratitude for the local services who have allowed us to work closely with them. David Oyeku who developed a prototype web-based interface for his masters thesis. This research was funded through the EPSRC Centre for Doctoral Training in Digital Civics (EP/L016176/1). Data supporting this publication is openly available under an 'Open Data Commons Open Database License'. Additional metadata are available at: http://dx.doi.org/10.17634/154300-40.

\section{REFERENCES}

1. Madeline Balaam, Rob Comber, Ed Jenkins, Selina Sutton, and Andy Garbett. 2015. FeedFinder : A Location-Mapping Mobile Application for 
Breastfeeding Women. Proceedings of the 33rd Annual ACM Conference on Human Factors in Computing Systems (CHI '15), 1709-1718. http://doi.org/http://dl.acm.org/citation.cfm?id=270 2123.2702328

2. Ana. Brandusescu, Renee. E. Sieber, and Sylvie. Jochems. 2015. Confronting the hype: The use of crisis mapping for community development. Convergence: The International Journal of Research into New Media Technologies: 1-17. http://doi.org/10.1177/1354856515584320

3. V Braun and V Clarke. 2006. Using thematic analysis in psychology. Qualitative research in psychology. Retrieved January 4, 2016 from http://www.tandfonline.com/doi/abs/10.1191/14780 88706qp063oa

4. Amy E Brown, Peter Raynor, David Benton, et al. 2010. Indices of Multiple Deprivation predict breastfeeding duration in England and Wales. European journal of public health 20, 2: 231-5. http://doi.org/10.1093/eurpub/ckp114

5. Wen-ying Sylvia Chou, Abby Prestin, Claire Lyons, and Kuang-yi Wen. 2013. Web 2.0 for health promotion: reviewing the current evidence. American journal of public health 103, 1: e9-18. http://doi.org/10.2105/AJPH.2012.301071

6. Crowdmap. 2016. Crowdmap. Retrieved from https://crowdmap.com/welcome

7. Christopher A. Le Dantec, Mariam Asad, Aditi Misra, and Kari E Watkins. 2015. Planning with Crowdsourced Data: Rhetoric and Representation in Transportation Planning. Proceedings of the 18th ACM Conference on Computer Supported Cooperative Work \& Social Computing - CSCW '15: 1717-1727. http://doi.org/10.1145/2675133.2675212

8. Christopher A. Le Dantec and Carl DiSalvo. 2013. Infrastructuring and the formation of publics in participatory design. Social Studies of Science. Retrieved January 11, 2016 from http://sss.sagepub.com/content/43/2/241.short

9. Christopher Le Dantec. 2012. Participation and publics: supporting community engagement. Proceedings of the 2012 ACM annual conference on Human Factors in Computing Systems - CHI '12, ACM Press, 1351. http://doi.org/10.1145/2207676.2208593

10. Carl DiSalvo. 2009. Design and the Construction of Publics. Design issues. Retrieved January 8, 2016 from http://www.mitpressjournals.org/doi/pdf/10.1162/de si.2009.25.1.48

11. Carl DiSalvo, Jonathan Lukens, Thomas Lodato,
Tom Jenkins, and Tanyoung Kim. 2014. Making public things: how HCI design can express matters of concern. Proceedings of the SIGCHI Conference on Human Factors in Computing Systems (CHI '14), ACM Press, 2397-2406. http://doi.org/10.1145/2556288.2557359

12. Carl DiSalvo, Jeff Maki, and Nathan Martin. 2007. MapMover: A Case Study of Design-Oriented Research into Collective Expression and Constructed Publics. Proceedings of the SIGCHI conference on Human factors in computing systems - CHI '07, ACM Press, 1249. http://doi.org/10.1145/1240624.1240813

13. Pelle Ehn. 2008. Participation in design things. 92 101. Retrieved January 11, 2016 from http://dl.acm.org/citation.cfm?id=1795234.1795248

14. Nahed Eltantawy and Julie B. Wiest. 2011. The Arab Spring| Social Media in the Egyptian Revolution: Reconsidering Resource Mobilization Theory. International Journal of Communication 5, $0: 18$.

15. Equality and Human Rights. 2010. Equality Act 2010. The Equality Act. Retrieved November 20, 2015 from http://www.calderstones.nhs.uk/media/files/Equalit y and Diversity/Equality Act 2010.pdf

16. FixMyStreet. FixMyStreet. Retrieved from https://www.fixmystreet.com/

17. Jeana H Frost and Michael P Massagli. 2008. Social uses of personal health information within PatientsLikeMe, an online patient community: what can happen when patients have access to one another's data. Journal of medical Internet research 10, 3: e15. http://doi.org/10.2196/jmir.1053

18. Andy Garbett, Rob Comber, Ed Jenkins, and Patrick Olivier. 2016. App Movement: A Platform for Community Commissioning of Mobile Applications. Proceedings of the 2016 CHI Conference on Human Factors in Computing Systems - CHI '16: 26-37.

19. William Gaver, Liliana Ovalle, Andy Boucher, et al. 2016. The Datacatcher: Batch Deployment and Documentation of 130 Location-Aware, Mobile Devices That Put Sociopolitically-Relevant Big Data in People's Hands: Polyphonic Interpretation at Scale. Proceedings of the 2016 CHI Conference on Human Factors in Computing Systems - CHI '16: 1597-1607. http://doi.org/10.1145/2858036.2858472

20. Lorna Gibson and VL Hanson. 2013. Digital motherhood: how does technology help new mothers? Proceedings of the SIGCHI Conference on Human Factors in Computing Systems - CHI '13, ACM Press., 313-322. 
21. Andrea Grimes, Martin Bednar, Jay David Bolter, and Rebecca E. Grinter. 2008. EatWell: Sharing Nutrition-Related Memories in a Low-Income Community. Proceedings of the ACM 2008 conference on Computer supported cooperative work - CSCW '08, ACM Press, 87. http://doi.org/10.1145/1460563.1460579

22. Andrea Grimes, Brian M. Landry, and Rebecca E. Grinter. 2010. Characteristics of shared health reflections in a local community. Proceedings of the 2010 ACM conference on Computer supported cooperative work - CSCW'10, ACM Press, 435. http://doi.org/10.1145/1718918.1718992

23. HarassMap. Sexual Harassment in Greater Cairo: Effectiveness of Crowdsourced Data. Towards a Safer City. Retrieved June 29, 2015 from http://harassmap.org/en/wpcontent/uploads/2013/03/Towards-A-SaferCity_full-report_EN-.pdf

24. HarassMap. Reconceptualizing Sexual Harassment in Egypt: A Longitudinal Assessment of elTaharrush el-Ginsy in Arabic Online Forums and Anti-Sexual Harassment Activism. Retrieved June 29, 2015 from http://harassmap.org/en/wpcontent/uploads/2013/03/ReconceptualizingSexual-Harassment-in-Egypt.pdf

25. Michael Hardey. 2008. Public health and Web 2.0. The Journal of the Royal Society for the Promotion of Health 128, 4: 181-189. http://doi.org/10.1177/1466424008092228

26. Mike Harding, Bran Knowles, Nigel Davies, and Mark Rouncefield. 2015. HCI, Civic Engagement $\&$ Trust. Proceedings of the 33rd Annual ACM Conference on Human Factors in Computing Systems - CHI '15: 2833-2842. http://doi.org/10.1145/2702123.2702255

27. Ian G Johnson, John Vines, Nick Taylor, Edward Jenkins, and Justin Marshall. 2016. Reflections on Deploying Distributed Consultation Technologies with Community Organisations. Proceedings of the 2016 CHI Conference on Human Factors in Computing Systems: 2945-2957. http://doi.org/10.1145/2858036.2858098

28. Rachel Keller. 2011. Using web 2.0 applications to increase local community wellbeing. Proceedings of the 25th BCS Conference on Human-Computer Interaction (BCS-HCI '11): 485-490. Retrieved January 14, 2015 from http://dl.acm.org/citation.cfm?id=2305316.2305404

29. Muin J Khoury and John P A Ioannidis. 2014. Medicine. Big data meets public health. Science (New York, N.Y.) 346, 6213: 1054-5. http://doi.org/10.1126/science.aaa2709

30. Stephen F King and Paul Brown. 2007. Fix My
Street or Else: Using the Internet to Voice Local Public Service Concerns. Proceedings of the 1st international conference on Theory and Practice of Electronic Governance: 72-80. http://doi.org/10.1145/1328057.1328076

31. Bruno Latour and Peter Weibel. 2005. Making Things Public: Atmospheres of Democracy. MIT Press. Retrieved July 20, 2015 from http://philpapers.org/rec/LATMTP

32. Michelina Mancuso, Xiaoquan Yao, Dan Otchere, et al. 2016. Proof of Concept Paper: NonTraditional Data Sources for Public Health Surveillance. Proceedings of the 6th International Conference on Digital Health Conference - DH'16, ACM Press, 91-92.

http://doi.org/10.1145/2896338.2896369

33. F McAndrew, J Thompson, and L Fellows. 2012. Infant feeding survey 2010. Leeds: Health and .... Retrieved August 18, 2015 from http:/www.hscic.gov.uk/catalogue/PUB08694/Infa nt-Feeding-Survey-2010-Consolidated-Report.pdf

34. Donald McMillan, Arvid Engström, Airi Lampinen, and Barry Brown. 2016. Data and the City. Proceedings of the 2016 CHI Conference on Human Factors in Computing Systems - CHI '16, ACM Press, 2933-2944. http://doi.org/10.1145/2858036.2858434

35. P. K H Mo and Neil S. Coulson. 2010. Empowering processes in online support groups among people living with HIV/AIDS: A comparative analysis of "lurkers" and "posters." Computers in Human Behavior 26, 5: 1183-1193. http://doi.org/10.1016/j.chb.2010.03.028

36. Andrew Monk and Steve Howard. 1998. Methods $\&$ tools: the rich picture: a tool for reasoning about work context. Interactions 5, 2: 21-30. http://doi.org/10.1145/274430.274434

37. Gina Neff. 2013. Why Big Data Won't Cure Us. Big data 1, 3: 117-123. http://doi.org/10.1089/big.2013.0029

38. Newcastle City Council. 2016. Newcastle City Council Budget 2016-2017.

39. William Odom, Ron Wakkary, Youn-kyung Lim, Audrey Desjardins, Bart Hengeveld, and Richard Banks. 2016. From Research Prototype to Research Product. Proceedings of the 2016 CHI Conference on Human Factors in Computing Systems - CHI '16: 2549-2561. http://doi.org/10.1145/2858036.2858447

40. Ory Okolloh. 2009. Ushahidi, or "testimony": Web 2.0 tools for crowdsourcing crisis information.

Participatory Learning and Action 59, January: 6570. 
41. Andrea G. Parker and Rebecca E. Grinter. 2014. Collectivistic health promotion tools: Accounting for the relationship between culture, food and nutrition. International Journal of HumanComputer Studies 72, 2: 185-206. http://doi.org/10.1016/j.jhcs.2013.08.008

42. Andrea Parker, Vasudhara Kantroo, Hee Rin Lee, Miguel Osornio, Mansi Sharma, and Rebecca Grinter. 2012. Health promotion as activism. Proceedings of the 2012 ACM annual conference on Human Factors in Computing Systems - CHI '12, ACM Press, 99. http://doi.org/10.1145/2207676.2207692

43. Patient Opinion. 2015. Patient Opinion. Retrieved from https://www.patientopinion.org.uk/

44. PatientsLikeMe. Live better, together! | PatientsLikeMe. Retrieved July 23, 2015 from https://www.patientslikeme.com/

45. Tim Regan, David Sweeney, John Helmes, Vasillis Vlachokyriakos, Siân Lindley, and Alex Taylor. 2015. Designing Engaging Data in Communities. Proceedings of the 33rd Annual ACM Conference Extended Abstracts on Human Factors in Computing Systems - CHI EA '15, ACM Press, 271-274. http://doi.org/10.1145/2702613.2725432

46. NC Rollins, N Bhandari, and N Hajeebhoy. 2016. Why invest, and what it will take to improve breastfeeding practices? The Lancet. Retrieved February 5, 2016 from http://www.sciencedirect.com/science/article/pii/S0 140673615010442

47. Jesper Simonsen and Toni Robertson. 2013. International Handbook of Participatory Design. Routledge.

48. Emma Simpson, Andrew Garbett, Rob Comber, and Madeline Balaam. 2016. Factors important for women who breastfeed in public: a content analysis of review data from FeedFinder. BMJ open 6, 10: e011762. http://doi.org/10.1136/bmjopen-2016011762

49. Robert Steele and Dan Dumbrell. 2012. Putting the public into public health information dissemination. Proceedings of the Seventeenth Australasian Document Computing Symposium on - ADCS '12, ACM Press, 135-138. http://doi.org/10.1145/2407085.2407104

50. Alex S. Taylor, Siân Lindley, Tim Regan, et al. 2015. Data-in-Place: Thinking through the Relations Between Data and Community. Proceedings of the 33rd Annual ACM Conference on Human Factors in Computing Systems - CHI '15, ACM Press, 2863-2872. http://doi.org/10.1145/2702123.2702558
51. Nick Taylor, Keith Cheverst, Peter Wright, and Patrick Olivier. 2013. Leaving the wild: lessons from community technology handovers. Proceedings of the SIGCHI Conference on Human Factors in Computing Systems - CHI '13, ACM Press, 1549-1558.

52. Nick Taylor, Justin Marshall, and A Blum-Ross. 2012. Viewpoint: empowering communities with situated voting devices. Proceedings of the SIGCHI Conference on Human Factors in Computing Systems - CHI '12: 1361-1370. http://doi.org/10.1145/2207676.2208594

53. Gill Thomson, Katherine Esbich-Burton, and Renee Flacking. 2014. Shame if you do, Shame if you don't: Women's experiences of infant feeding. Maternal And Child Nutrition. Retrieved August 18, 2015 from http://clok.uclan.ac.uk/12089/3/12089_Thompson.p $\mathrm{df}$

54. TripAdvisor. 2017. TripAdvisor. Retrieved from https://www.tripadvisor.co.uk/

55. C F van Uden-Kraan, C H Drossaert, E Taal, B R Shaw, E R Seydel, and M A van de Laar. 2008.

Empowering processes and outcomes of participation in online support groups for patients with breast cancer, arthritis, or fibromyalgia. Qualitative Health Research 18, 3: 405-417. http://doi.org/18/3/405 [pii] \r10.1177/1049732307313429

56. UNICEF. Baby Friendly Initiative. Retrieved from http://www.unicef.org.uk/babyfriendly/

57. Vasilis Vlachokyriakos, Rob Comber, Karim Ladha, et al. 2014. PosterVote. Proceedings of the 2014 conference on Designing interactive systems DIS '14, ACM Press, 795-804. http://doi.org/10.1145/2598510.2598523

58. Vasilis Vlachokyriakos, Clara Crivellaro, Christopher A. Le Dantec, Eric Gordon, Pete Wright, and Ol. 2016. Digital Civics : Citizen Empowerment. CHI Extended Abstracts on Human Factors in Computing Systems: 1096-1099.

59. Yelp. 2017. YELP. Retrieved from https://www.yelp.co.uk

60. Matthew Zook, Mark Graham, Taylor Shelton, and Sean Gorman. 2010. Volunteered geographic information and crowdsourcing disaster relief: a case study of the Haitian earthquake. World Medical \& Health Policy 2: 7-33. http://doi.org/10.2202/1948-4682.1069 